\title{
Visual and acoustic signaling in three species of Brazilian nocturnal tree frogs (Anura, Hylidae)
}

\section{Luís Felipe Toledoํㅡㄹ Olívia G. S. Araújo ${ }^{1}$, Lorena D. Guimarães², Rodrigo Lingnau ${ }^{3}$, and} Célio F. B. Haddad ${ }^{1}$

1 Departamento de Zoologia, Instituto de Biociências, Universidade Estadual Paulista. Caixa Postal 199, 13506-970, Rio Claro, SP, Brazil. E-mail: toledolf2@yahoo.com.

2 Departamento de Biologia, Instituto de Biociências, Universidade Federal de Goiás. Caixa Postal 131, 74001-970, Goiânia, GO, Brazil.

${ }^{3}$ Laboratório de Herpetologia, Museu de Ciências e Tecnologia \& Faculdade de Biociências, Pontifícia Universidade Católica do Rio Grande do Sul. Av. Ipiranga, 6681, 90619-900, Porto Alegre, RS, Brazil.

\begin{abstract}
Visual and acoustic signaling in three species of Brazilian nocturnal tree frogs (Anura, Hylidae). Visual communication seems to be widespread among nocturnal anurans, however, reports of these behaviors in many Neotropical species are lacking. Therefore, we gathered information collected during several sporadic field expeditions in central and southern Brazil with three nocturnal tree frogs: Aplastodiscus perviridis, Hypsiboas albopunctatus and $H$. bischoffi. These species displayed various aggressive behaviors, both visual and acoustic, towards other males. For A. perviridis we described arm lifting and leg kicking; for $H$. albopunctatus we described the advertisement and territorial calls, visual signalizations, including a previously unreported behavior (short leg kicking), and male-male combat; and for $\mathrm{H}$. bischoffi we described the advertisement and fighting calls, toes and fingers trembling, leg lifting, and leg kicking. We speculate about the evolution of some behaviors and concluded that the use of visual signals among Neotropical anurans may be much more common than suggested by the current knowledge.
\end{abstract}

Keywords: Anura, Hylidae, Aplastodiscus perviridis, Hypsiboas albopunctatus, Hypsiboas bischoffi, visual and acoustic signaling, agonistic interactions, physical combats.

\section{Introduction}

Visual communication was first described for diurnal anurans and seems to be widely distributed among them (review in Hödl and Amézquita 2001). However, it has been recently

Received 3 August 2006.

Accepted 7 February 2007.

Distributed June 2007. observed that some nocturnal species also perform visual communication (e.g., Bertoluci 2002; Abrunhosa and Wogel 2004; Hartmann et al. 2005, Giasson and Haddad 2006). Visual communication is usually associated with reproduction (e.g., for female attraction) or aggressive interactions related to territoriality (Hödl and Amézquita 2001, Rosenthal et al. 2004), but also with predation (Bertoluci 2002) and intraspecific communication (Abrunhosa 
and Wogel 2004). Currently, a total of 27 visual displays have been described, including leg stretching, throat display, toe/fingers trembling, and body rising (Hödl and Amézquita 2001, Bertoluci 2002; Abrunhosa and Wogel 2004; Hartmann et al. 2005, Hirschmann and Hödl 2006). Although these behaviors are complex and apparently widespread, their origin is often difficult to access, despite the efforts of Hödl and Amézquita (2001).

We present new observations on the nocturnal visual signaling of three hylid species: Aplastodiscus perviridis, Hypsiboas albopunctatus, and $H$. bischoffi. Although territorial vocalizations have been reported to exist in the repertoire of $H$. albopunctatus (Haddad et al. 1988, Bastos et al. 2003), no other information is available for the remaining taxa. Visual signaling has not been described for any of these species. Only one report of visual signaling has been made to date for Aplastodiscus [A. eugenioi in Hartmann et al. 2004 as Hyla sp. (aff. ehrhardti)], and one for Hypsiboas ( $H$. albomarginatus in Giasson and Haddad 2006). Both were observed during aggressive interactions. Besides providing direct observations of visual and aggressive interactions for the studied taxa, we described novel vocalizations (territorial and fighting calls) for two of those species, and suggest new hypotheses for the origin of the visual signals herein described.

\section{Material and Methods}

We gathered information collected during several sporadic field expeditions in central and southern Brazil. Observations of Aplastodiscus perviridis were made on 8 March 2006 at Fazenda São Francisco, Municipality of Ponte Serrada, State of Santa Catarina. Observations of Hypsiboas albopunctatus occurred in March 2002 at Municipality of Mineiros, State of Goiás, in June 2005 at Municipality of Santana do Riacho (Serra do Cipó), State of Minas Gerais, and in February 2006 at Municipality of Santa Rita do Passa Quatro (Parque Estadual de
Vassununga - PEV), State of São Paulo. Observations of $H$. bischoffi occurred in December 2005 at Municipality of Treviso, State of Santa Catarina, and in September 2003 at Municipality of Iporanga (Parque Estadual Turístico do Alto Ribeira - PETAR), State of São Paulo. Sampling methods included ad libitum, focal-animal, all occurrences of some behaviors, and sequences (Altmann 1974; Lehner 1996). For Hypsiboas albopunctatus, aggressive behaviors were stimulated by playback of advertisement and territorial calls, or by placing a conspecific male about $20 \mathrm{~cm}$ from the resident calling male. With the remaining species no manipulation was made. The terminology for describing visual signaling follows that presented by Hödl and Amézquita (2001) complemented by Hartman et al. (2005).

Aggressive vocalizations were recorded with a Marantz cassette tape recorder (PMD222), equipped with an external directional microphone (Audiotecnica AT835b) positioned ca. $50 \mathrm{~cm}$ from the calling male. We used chrome cassette tapes at $4.75 \mathrm{~cm} / \mathrm{s}$. We analyzed the calls using Raven 1.2 software (16 bits of resolution, $44 \mathrm{kHz}$ of frequency sampling, FFT and frame length of 256 samples). The terminology for the vocal analysis followed that presented in Toledo and Haddad (2005), except for "pseudonotes", which was considered group of pulses within a note, accordingly to Heyer et al. (1990). Visual signaling of all species was recorded in video cameras and the files are available upon request.

\section{Results}

Under natural conditions, all species displayed various aggressive behaviors, both visual and acoustic, towards other males. The same happened in response to encounters provoked by the introduction of a conspecific male, as well as when males were apparently isolated from a group or potential competitor. Playback of advertisement and/or territorial calls also stimulated aggressive reactions. The visual 


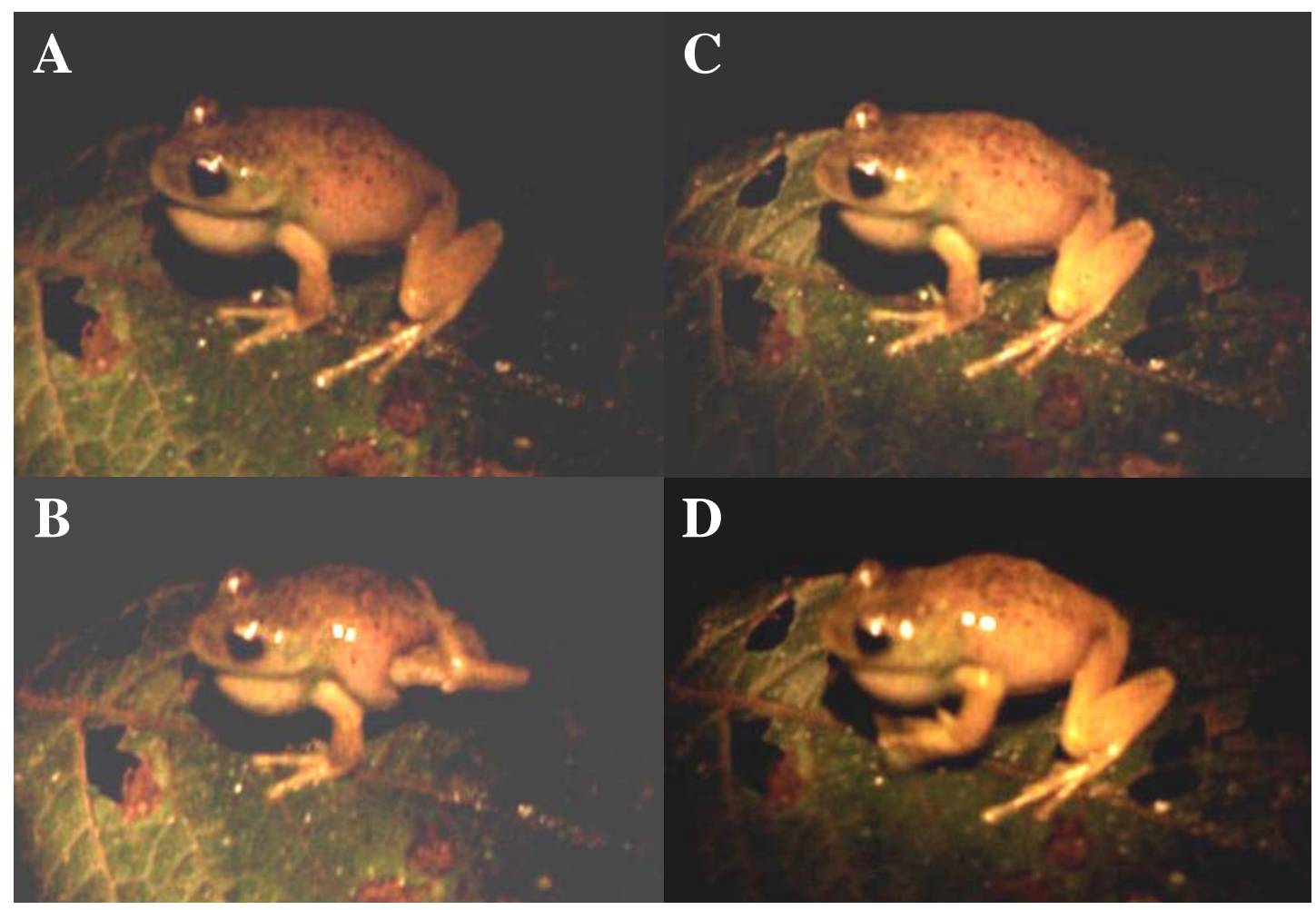

Figure 1 - Adult male of Aplastodiscus perviridis performing leg kicking (initial position and visual signal: A and B, respectively) and arm lifting (initial position and visual signal: $\mathrm{C}$ and $\mathrm{D}$, respectively). Observations made at Fazenda São Francisco, Municipality of Ponte Serrada, State of Santa Catarina, Southern Brazil.

signals observed were leg kicking, limb lifting (sensu Hartmann et al. 2005), and toe/fingers trembling (sensu Hödl and Amézquita 2001).

Two males of $A$. perviridis were observed calling in temporary water bodies inside an artificial channel at the edge of a small road. One of the males displayed visual signals while perched on a leaf $20 \mathrm{~cm}$ above the ground. The second male was calling while perched on a leaf $15 \mathrm{~cm}$ above the ground and $3 \mathrm{~m}$ apart from the first one. Male number one emitted 44 advertisement calls within a 43-second period and displayed leg kicks with both hind limbs, as well as arm lifting, in no particular order. It started by kicking its left leg, and repeated it four, eight, and 19 seconds later. It then lifted the left arm and kicked its right leg. After 18 seconds, it kicked its left leg (Figure 1). No other male or female was seen in the vicinity.

Males of $H$. albopunctatus were calling while perched $1 \mathrm{~m}$ from the ground on the margins of temporary ponds, permanent ponds, and rivulets with very low water flow. A higher density of males was usually observed the day after a rain. When calling, males exhibited bright white to yellow colorful spots and stripes on the femoral region and on the inguinal region, respectively (Figure 2A). We observed visual displays when males of $H$. albopunctatus were introduced near conspecific males and during playbacks. The visual signaling of $H$. albopunctatus seems to be performed in an escalated ordination: initially males trembled their fingers $(n=5)$, than turned toward the 


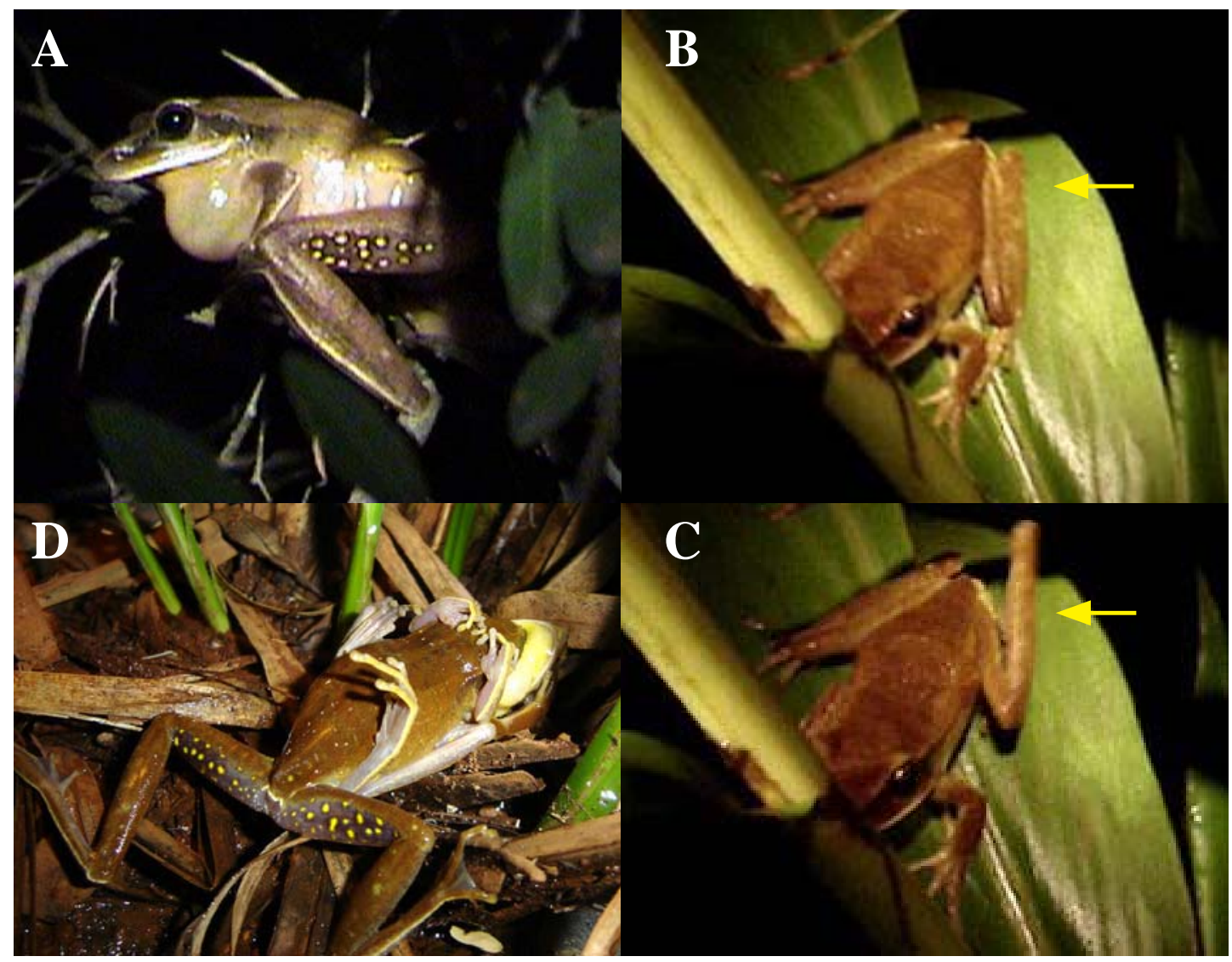

Figure 2 - Adult males of Hypsiboas albopunctatus performing visual displays (A-C) and fighting (D). Male calling and displaying bright spots in femoral region and bright stripes in inguinal region (A); male during agonistic interaction prior to (B) and during short leg kicking (C). Observations were made in the Municipality of Santa Rita do Passa Quatro (B-C), State of São Paulo, and Municipality of Santana do Riacho (A and D), State of Minas Gerais, southeastern Brazil.

intruder male (introduced by us in the territory of the resident male, $n=2)$, lifted an arm ( $n=$ $2)$, performed a short leg kick $(n=11)$, and finally initiated physical combat with the intruder male ( $\mathrm{n}=2$ in provoked encounters and $\mathrm{n}=2$ in natural conditions). This sequence of displays was observed twice in the same night with two different resident males. Physical combats occurred among males perched on the bushes $(n=3)$ and on the floor $(n=1)$. In one case, the resident male pursuited the intruder before combat. During the fight, both males hugged face-to-face (Figure 2D) and tried to throw the opponent out of its calling site through hind leg kicking. Males also used their prepollical spines to cause injuries in the opponent (see Figure 2D). Scars were commonly observed in males of $H$. albopunctatus. The short leg kicks observed seems to correspond to that described by Hartmann et al. (2005). However, the males do not extend the entire leg backwards, but only partially. In its maximum 


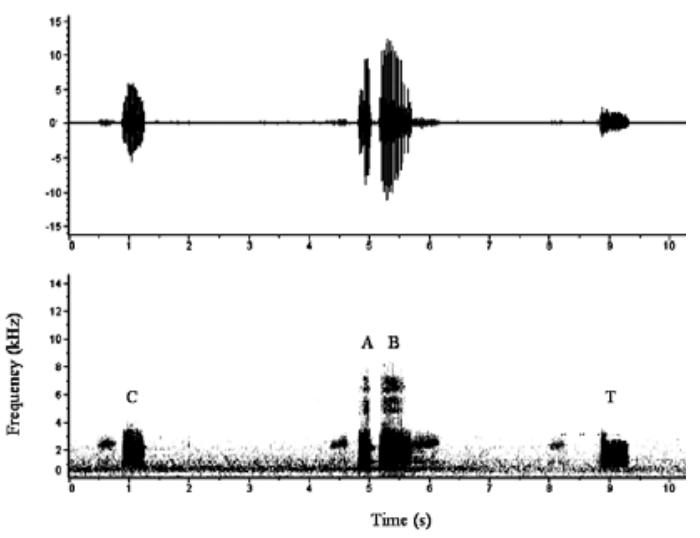

Figure 3 - Waveform (above) and spectrogram (below) of the advertisement call (notes "A" to "C") and territorial call (note " $\mathrm{T}$ ”) of Hypsiboas albopunctatus, recorded at Municipality of Santa Rita do Passa Quatro, State of São Paulo, Southeastern Brazil; air temperature: $24^{\circ} \mathrm{C}$.

extension, the tibia achieved an angle of approximately $45^{\circ}$ with the tarsus, and the foot touched the leave where the frog was located (Figures 2B-C).

We recognized three types of notes (notes

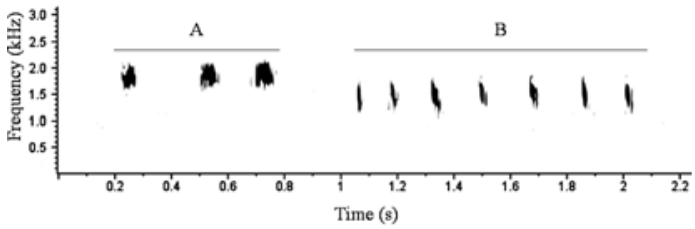

Figure 4 - Spectrogram of the initial note of the advertisement call (A) and the fighting call (B) of Hypsiboas bischoffi, recorded at Parque Estadual Turístico do Alto Ribeira (PETAR), Municipality of Iporanga, State of São Paulo, Southeastern Brazil; air temperature: $22^{\circ} \mathrm{C}$.

"A", "B", and "T") in the vocalizations of $H$. albopunctatus (Figure 3). A fourth type of note (note "C") seems to be one of the two advertisement notes (A or B) emitted weakly and in isolation. Notes " $A$ " and " $B$ " had low energy frequencies above $3.6 \mathrm{kHz}$ (Table 1; Figure 3), and can be considered side band series due to the pulsatile nature of the call (see Heyer et al. 1990). These notes were described by different authors: Haddad et al. (1988), Heyer et al. (1990), De la Riva et al. (1997), Kwet et al. (2002), and Bastos et al. (2003).

Table 1 - Notes of Hypsiboas albopunctatus calls recorded at Parque Estadual de Vassununga, Municipality of Santa Rita do Passa Quatro, State of São Paulo, southeastern Brazil (air temperature: $24^{\circ} \mathrm{C}$ ). Values presented as mean \pm standard deviation (range).

\begin{tabular}{|c|c|c|c|c|c|c|}
\hline \multirow[t]{2}{*}{ Note type } & \multicolumn{4}{|c|}{ Frequency $(\mathbf{k H z})$} & \multirow{2}{*}{$\begin{array}{c}\text { Duration } \\
\text { (s) }\end{array}$} & \multirow{2}{*}{$\begin{array}{l}\text { Number of } \\
\text { pseudonotes }\end{array}$} \\
\hline & Minimum & Maximum & Dominant & Low power & & \\
\hline Territorial "T" & $0.72 \pm 0.09$ & $2.98 \pm 0.25$ & $1.17 \pm 0.24$ & - & $0.43 \pm 0.03$ & - \\
\hline$(\mathrm{N}=11)$ & $(0.58-0.85)$ & $(2.47-3.41)$ & $(1.03-1.89)$ & & $(0.39-0.47)$ & \\
\hline Advertisement " $A$ " & $0.68 \pm 0.06$ & $3.62 \pm 0.16$ & $2.22 \pm 0.08$ & $5.90 \pm 1.94$ & $0.25 \pm 0.04$ & $5 \pm 0.8$ \\
\hline$(\mathrm{N}=4)$ & $(0.62-0.77)$ & $(3.49-3.85)$ & $(2.15-2.33)$ & $(3.64-7.99)$ & $(0.21-0.30)$ & $(4-6)$ \\
\hline Advertisement "B" & $0.64 \pm 0.01$ & $3.43 \pm 0.25$ & $2.21 \pm 0.136$ & $5.80 \pm 1.53$ & $0.51 \pm 0.04$ & $15 \pm 4.2$ \\
\hline$(\mathrm{N}=9)$ & $(0.51-0.87)$ & $(2.90-3.74)$ & $(1.98-2.33)$ & $(3.99-8.27)$ & $(0.42-0.55)$ & $(8-20)$ \\
\hline Weak note "C" & $0.62 \pm 0.20$ & $3.47 \pm 0.39$ & $2.20 \pm 0.08$ & - & $0.40 \pm 0.04$ & $13 \pm 0.82$ \\
\hline$(\mathrm{N}=4)$ & $(0.36-0.79)$ & $(3.13-4.02)$ & $(2.15-2.32)$ & & $(0.37-0.46)$ & $(12-14)$ \\
\hline
\end{tabular}



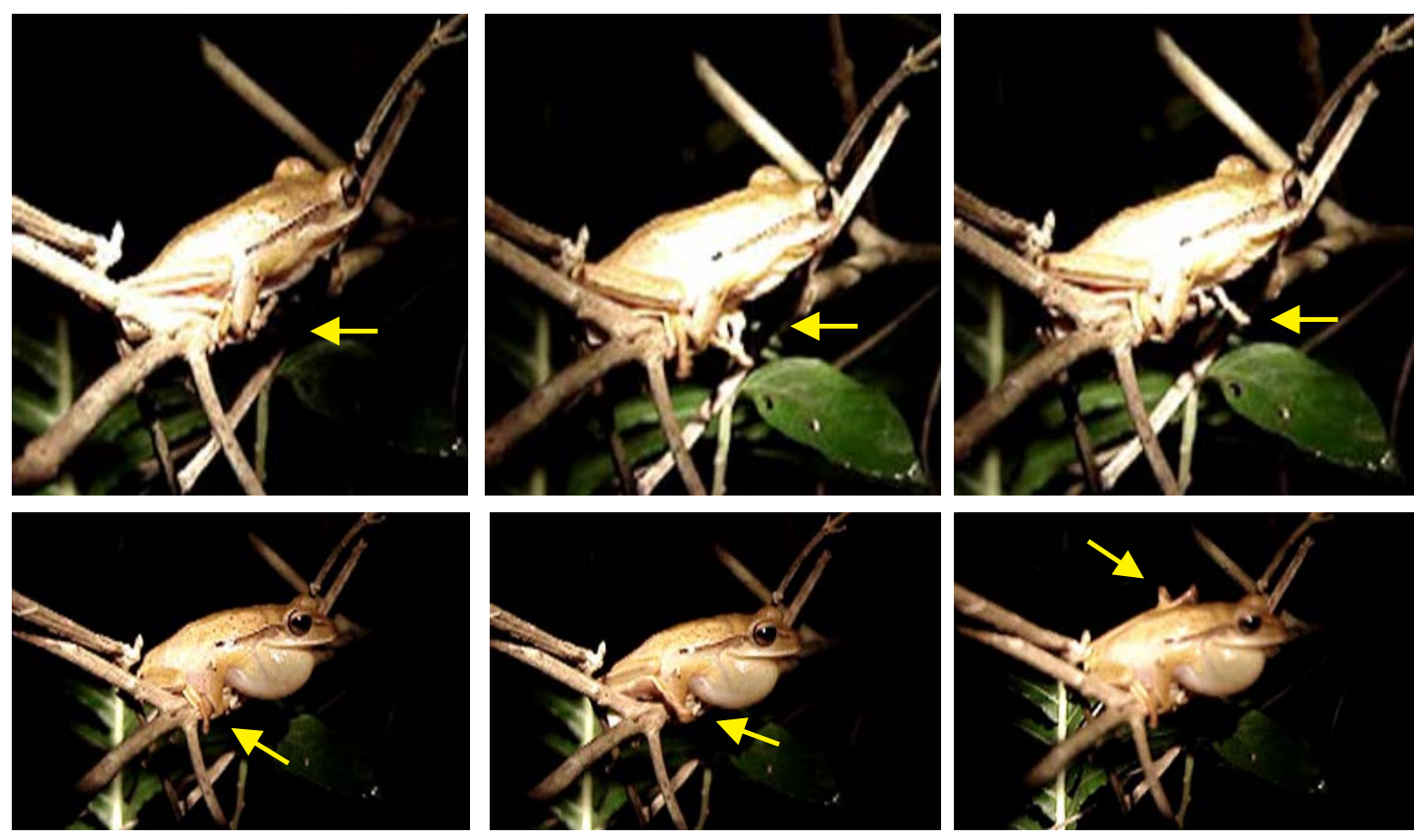

Figure 5 - Two sequences of visual displays in Hypsiboas bischoffi stimulated by playback of advertisement call of the same individual. A) Initial position of the first sequence; B) trembling of right toes; C) trembling of left fingers; D) initial position of the second sequence; E) right leg lifting; F) left leg kicking. Observations were made at the Municipality of Treviso, State of Santa Catarina, Southern Brazil.

Note "T" was considered to have a territorial function since its rate of emission in provoked encounters increased considerably when another male was placed nearby. Its emission rate also increased in response to playbacks of any type of vocalizations, even those including the other types of notes. Territorial notes were pulsed (ca. 80 pulses per note) and emitted in a low frequency (ca. $1 \mathrm{kHz}$ ). The amplitude of frequencies ranged from 0.58 to $3.41 \mathrm{kHz}$, with the notes been emitted during 0.43 seconds on average (Table 1; Figure 3). In two cases, males emitted several sequences of notes “T”. Males also were able to make multiple combinations of these notes. The most commonly heard phrases were “AB”, but “TB”, “TBB”, and "ABT” were also heard.

Males of $H$. bischoffi called while observed at about $1 \mathrm{~m}$ from the ground, around the edges of lentic water bodies (temporary or permanent ponds, and rivulets with very low water flow). Their advertisement call includes two types of notes. An initial note (Figure 4A), of mean dominant frequency of $1.894 \mathrm{kHz}$ (frequency range $=1.572$ to $2.092 ; \mathrm{N}=8$ ), was emitted in isolation or preceding a warbling series of 15 to 20 short notes (see descriptions in Bokermann 1967; Heyer et al. 1990 as Hyla multilineata). When stimulated by playback of their own advertisement calls, two males displayed leg kicking, foot lifting, and finger and toe trembling (Figure 5). Physical combat was also observed between two males on a second night. When the intruder male approached a resident of a calling site, the later started to emit a group of initial notes (Figure 4A) and chased the intruder into a shrub over a flooded ground. Both males underwent physical interactions, assuming the 
same position described for $H$. albopunctatus. During the fight both individuals emitted two series of seven notes as a fighting call (Figure 4B). These notes were spaced by 147 milliseconds (range $=112-119 ; \mathrm{SD}=22.9 ; \mathrm{n}=$ 12). Each note had a mean dominant frequency of $1.47 \mathrm{kHz}$ (range $=1.29-1.55$; $\mathrm{SD}=0.06$; $\mathrm{n}$ = 14), mean minimum frequency of $1.168 \mathrm{kHz}$ (range $=1.063-1.262 ; \mathrm{SD}=0.06 ; \mathrm{n}=14)$, and mean maximum frequency of $1.765 \mathrm{kHz}$ (range $=1.609-1.871 ; \mathrm{SD}=0.07 ; \mathrm{n}=14$ ).

\section{Discussion}

Our observations provide new evidences that nocturnal visual signaling may be more frequent than previously believed (see also Hartmann et al. 2005, Giasson and Haddad 2006). More data should be generated in the near future, enabling broader analyses and inferences (Hödl and Amézquita 2001). By now, we can suggest some new hypotheses about the origin of these visual behaviors and propose a new nomenclature for a previously undescribed behavior. Visual signals are believed to be derived from pre-existing movements (Hödl and Amézquita 2001). For example, arm waving, hind-feet lifting, limb lifting, and leg kicking may be related to movements produced during physical interactions between males (Hödl and Amézquita 2001, Giasson and Haddad 2006). Following the same criteria, we suggest that fingers trembling may be originated from movements of comfort. Similar movements can be observed when the individuals are changing their positions and postures on the vegetation (pers. obs.). Males usually turn towards their opponents just before initiating a physical fight (Abrunhosa and Wogel 2004, present study). Therefore, fingers trembling could indicate a change in the position of the anuran as a prelude to the movement toward the opponent's direction. Interpreting this signal as one of the last stages of nonphysical agonistic interactions could prevent fights and the costs associated to them (e.g., Kluge 1981, Martins and Haddad 1988, Wells
1988). Short leg kicking, as described here for $H$. albopunctatus, may be referred as a new visual display since it does not fit in any previously proposed category (Hödl and Amézquita 2001, Hartmann et al. 2005). Its origin and function seem to be the same as those suggested for leg kicking or arm waving, for example (see above), therefore it may also prevent physical combats.

Visual signaling tied to complex courtship behavior has been reported to occur in Aplastodiscus eugenioi (Hartmann et al. 2004). Complex courtship behavior was also reported for $A$. perviridis, which involves tactile stimuli and vocalizations, but without reports of visual signals (Haddad et al. 2005). Moreover, there have been no reports of signal use between males in the absence of females as observed by us for $A$. perviridis. We suggest that the visual signaling observed here for $A$. perviridis could be related to inter-male territoriality, as observed in other species discussed by us.

All the three species herein studied (Aplastodiscus perviridis, Hypsiboas albopunctatus, and $H$. bischoffi) make use of a combination of visual and acoustic signaling. The aggressiveness of the males can be escalated, ranging from territorial vocalizations to signals that prelude fights, such as fingers trembling and leg kicking. By having complex calls with different notes, males can intensify the signal that they want to communicate (e.g. Cardoso \& Haddad 1984, Lingnau et al. 2004). In the present study, $H$. albopunctatus increased the emission of aggressive notes when another male was nearby. The same situation has been observed for several other hylid species, such as Dendropsophus minutus (Cardoso \& Haddad 1984), Hypsiboas albomarginatus (Giasson and Haddad 2006), and Scinax fuscomarginatus (Toledo and Haddad 2005). The use of visual signals among Neotropical anurans may be much more common than suggested by currently knowledge, reinforcing the need of extensive studies and reports, such as the present one. 


\section{Acknowledgements}

We are grateful to Luís O. M. Giasson, Ivan Sazima, and two anonymous referees for the discussion and suggestions on early versions of the manuscript. Luís O. M. Giasson assisted with field activities. Fabrício Oda provided the picture of the fighting males of Hypsiboas albopunctatus. RAN-IBAMA (IBAMA/RAN 183/05) and COTEC-IF provided necessary collecting permits. CAPES and CNPq granted scholarships; Biota-FAPESP (proc. n. 01/133413) and CNPq (bolsa de produtividade em pesquisa to $\mathrm{CFBH}$ ) funded the CFBH's herpetology laboratory. LFT also tanks Idea Wild, Neotropical Grassland Conservancy for equipment donation, and the Bioacustics Research Program of the Cornell Laboratory of Ornithology for the software license granted.

\section{References}

Abrunhosa, P.A. and H. Wogel. 2004. Breeding behavior of the leaf-frog Phyllomedusa burmeisteri (Anura: Hylidae). Amphibia-Reptilia 25: 125-135.

Altmann, J. 1974. Observational study of behavior: sampling methods. Behaviour 15: 227-267.

Bastos R. P., M. A. F. Bueno, S. L. Dutra, and L. P. Lima. 2003. Padrões de vocalização de anúncio em cinco espécies de Hylidae (Amphibia: Anura) do Brasil central. Comunicação do Museu de Ciências e Tecnologia PUCRS, Série Zoologia 16: 39-51.

Bertoluci, J. 2002. Pedal luring in the leaf-frog Phyllomedusa burmeisteri (Anura, Hylidae, Phyllomedusinae). Phyllomedusa 1: 93-95.

Bokermann, W. C. A. 1967. Notas sôbre cantos nupciais de anfíbios brasileiros (Anura). III. Anais da Academia Brasileira de Ciências 39: 491-493.

Cardoso, A. J. and C. F. B. Haddad. 1984. Variabilidade acústica em diferentes populações e interações agressivas de Hyla minuta (Amphibia, Anura). Ciência e Cultura 36: 1393-1399.

De la Riva I., R. Márquez and J. Bosch. 1997. Description of the advertisement calls of some South American Hylidae (Amphibia, Anura): taxonomic and methodological consequences. Bonner Zoologische Beiträge 47: 175-185.

Giasson, L. O. M. and C. F. B. Haddad. 2006. Social Interactions in Hypsiboas albomarginatus (Anura: Hylidae) and the significance of acoustic and visual signals. Journal of Herpetology 40: 171-180.
Haddad C. F. B., G. V. Andrade and A. J. Cardoso. 1988. Anfíbios anuros no Parque Nacional da Serra da Canastra, Estado de Minas Gerais. Brasil Florestal 64: 9-20.

Haddad, C. F. B., J. Faivovich and P. C. A. Garcia. 2005. The specialized reproductive mode of the treefrog Aplastodiscus perviridis (Anura: Hylidae). AmphibiaReptilia 26: 87-92.

Hartmann, M. T., P. A. Hartmann and C. F. B. Haddad. 2004. Visual signaling and reproductive biology in the nocturnal treefrog, Hyla sp. (aff. ehrhardti) (Anura: Hylidae). Amphibia-Reptilia 25: 395-406.

Hartmann, M. T., L. O. M. Giasson, P. A. Hartmann, and C. F. B. Haddad. 2005. Visual communication in Brazilian species of anurans from the Atlantic forest. Journal of Natural History 39: 1675-1685.

Heyer, R. W., A. S. Rand, C. A. G. Cruz, O. L. Peixoto, and C. E. Nelson. 1990. Frogs of Boracéia. Arquivos de Zoologia, São Paulo 31: 231-410.

Hirschmann, W. and W. Hödl. 2006. Visual signaling in Phrynobatrachus krefftii Boulenger, 1909 (Anura: Ranidae). Herpetologica 62: 18-27.

Hödl, W. and A. Amézquita. 2001. Visual signaling in anuran amphibians. Pp. 121-141 in M. J. Ryan (ed.), Anuran Communication. Washington. Smithsonian Institution Press.

Kluge, A. G. 1981. The life history, social organization, and parental behavior of Hyla rosenbergi Boulenger, a nest building gladiator frog. Miscellaneous Publications, Museum of Zoology, University of Michigan 160: 1-170.

Kwet, A., M. Solé, T. Miranda, J. Melchiors, D. E. Naya and R. Maneyro. 2002. First record of Hyla albopunctata Spix, 1824 (Anura: Hylidae) in Uruguay, with comments on the advertisement call. Boletín de la Asociación Herpetológica Española 13: 15-19.

Lehner, P. N. (ed). 1996. Handbook of Ethological Methods. Cambridge. Cambridge University Press. 672 pp.

Lingnau, R., L. D. Guimarães and R. P. Bastos. 2004. Vocalizações de Hyla werneri (Anura, Hylidae) no sul do Brasil. Phyllomedusa 3: 115-120.

Martins, M. and C. F. B. Haddad. 1988. Vocalizations and reproductive behaviour in the smith frog, Hyla faber Wied (Amphibia: Hylidae). Amphibia-Reptilia 9: 49-60.

Rosenthal G. C., A. S. Rand and M. J. Ryan. 2004. The vocal sac as a visual cue in anuran communication: an experimental analysis using video playback. Animal Beahaviour 68: 55-58.

Toledo, L. F. and C. F. B. Haddad. 2005. Acoustic repertoire and calling site of Scinax fuscomarginatus (Anura, Hylidae). Journal of Herpetology 39: 455-464.

Wells, K. D. 1988. The effect of social interactions on anuran vocal behavior. Pp. 433-454 in B. Fritzsch, M. J. Ryan, W. Wilczynski, T. E. Hetherington, and W. Walkowiak (eds.), The Evolution of the Amphibian Auditory System. New York. John Wiley and Sons. 